\title{
Horizontal Gene Transfer in Nematodes: A Catalyst for Plant Parasitism?
}

\author{
Annelies Haegeman, ${ }^{1}$ John T. Jones, ${ }^{2}$ and Etienne G. J. Danchin ${ }^{3}$ \\ ${ }^{1}$ Department of Molecular Biotechnology, Ghent University, Coupure links 653, 9000 Ghent, Belgium; ${ }^{2}$ Plant Pathology \\ Department, SCRI, Invergowrie, Dundee, DD2 5DA, U.K.; ${ }^{3}$ INRA UMR 1301, CNRS UMR 6243, UNSA, 400 route des \\ Chappes, F-06903 Sophia-Antipolis, France
}

Submitted 8 March 2011. Accepted 5 April 2011.

\begin{abstract}
The origin of plant parasitism within the phylum Nematoda is intriguing. The ability to parasitize plants has originated independently at least three times during nematode evolution and, as more molecular data has emerged, it has become clear that multiple instances of horizontal gene transfer (HGT) from bacteria and fungi have played a crucial role in the nematode's adaptation to this new lifestyle. The first reported HGT cases in plant-parasitic nematodes were genes encoding plant cell wall-degrading enzymes. Other putative examples of HGT were subsequently described, including genes that may be involved in the modulation of the plant's defense system, the establishment of a nematode feeding site, and the synthesis or processing of nutrients. Although, in many cases, it is difficult to pinpoint the donor organism, candidate donors are usually soil dwelling and are either plant-pathogenic or plant-associated microorganisms, hence occupying the same ecological niche as the nematodes. The exact mechanisms of transfer are unknown, although close contacts with donor microorganisms, such as symbiotic or trophic interactions, are a possibility. The widespread occurrence of horizontally transferred genes in evolutionarily independent plant-parasitic nematode lineages suggests that HGT may be a prerequisite for successful plant parasitism in nematodes.
\end{abstract}

The plant cell wall represents a formidable barrier to any potential pathogen that aims to use plants as a food source. Although fungal and bacterial plant pathogens possess a battery of enzymes that allow them to break down the plant cell wall (Walton 1994), it was assumed that animals had not evolved this capacity. Instead, animals that need to metabolize the cell wall were thought to recruit symbiotic microorganisms. So, although it was known many years ago that protein extracts of plant-parasitic nematodes contain cellulase activity (Dropkin 1963), little significance was attached to these observations. However, the first parasitism genes characterized from plantparasitic nematodes (PPN) were found to encode functional and endogenous cellulases secreted from the subventral esophageal gland cells that were used to break down the plant cell

All authors contributed equally.

Corresponding author: Etienne G. J. Danchin:

E-mail: etienne.danchin@sophia.inra.fr

* The $e$-Xtra logo stands for "electronic extra" and indicates that Figure 2 appears in color online. wall (Smant et al. 1998). The discovery of the nematode cellulases, their similarity to bacterial genes, and the absence of similar genes from all other nematodes studied at the time led to the hypothesis that they had been acquired from bacteria through horizontal gene transfer (HGT) (Keen and Roberts 1998).

HGT can be defined as the asexual movement of genetic material between different species, regardless of the evolutionary distance between them. HGT is very common within bacteria, and considerable proportions of most bacterial genomes consist of horizontally-acquired genes (Nakamura et al. 2004). By contrast, reported cases of HGT between microorganisms and animals are rare. This may be due to several reasons. First, in animals with a separate germline, the transfer event has to occur in the germline, and exposure of these tissues to foreign DNA is often limited. In addition, the foreign DNA needs to be successfully incorporated into the genome in a manner that allows one or more of the encoded genes to be expressed as one or more functional proteins. Given the differences in gene structure and organization between eukaryotes and bacteria, this is likely to be a significant limitation. Moreover, unless there is an evolutionary advantage associated with the gene product, the newly transferred gene may not become fixed in the population. Finally, it is possible that HGT from bacteria to animals is more widespread than is currently appreciated; only a few genomes have been sequenced to date, and even where genome information is available, it may not have been studied in detail for HGT events (Andersson 2005; Dunning Hotopp 2011; Keeling and Palmer 2008). In reported cases of HGT between bacteria and eukaryotes, there is a tendency for preferential acquisition of genes that allow specialization and adaptation of the recipient to a new environment (Keeling and Palmer 2008). It is, therefore, possible that HGT allows specializations to evolve, and plant parasitism by nematodes may well be another case in point. Plant parasitism in nematodes has arisen independently at least three times during evolution (Blaxter et al. 1998; van Megen et al. 2009) (Fig. 1), and there is evidence that HGT may have played a key role on at least two of these occasions.

Cases of HGT in plant-parasitic nematodes.

Genome sequencing or large-scale expressed sequence tag (EST) projects have now been applied to many PPN, and large numbers of genes potentially acquired by HGT have been identified from several different clades, although the strictest criteria supporting acquisition by HGT (Keeling and Palmer 2008) have not always been applied. Criteria supporting HGT 
should ideally include phylogenetic methods, extensive analysis of distribution that reveals absence in related species, and habitat overlap between donor and recipient (Mitreva et al. 2009).

The most economically important PPN are found in clade 12 (van Megen et al. 2009) (Fig. 1), which will be referred to here as the Tylenchida (terminology and classification used throughout this article is based on that of van Megen and associates [2009], although many taxonomic issues remain a matter of debate). This clade, which includes the cyst nematodes (CN) and the root-knot nematodes (RKN) as well as numerous genera of migratory endoparasites, has been extensively analyzed using genomics and transcriptomics approaches. Consequently,

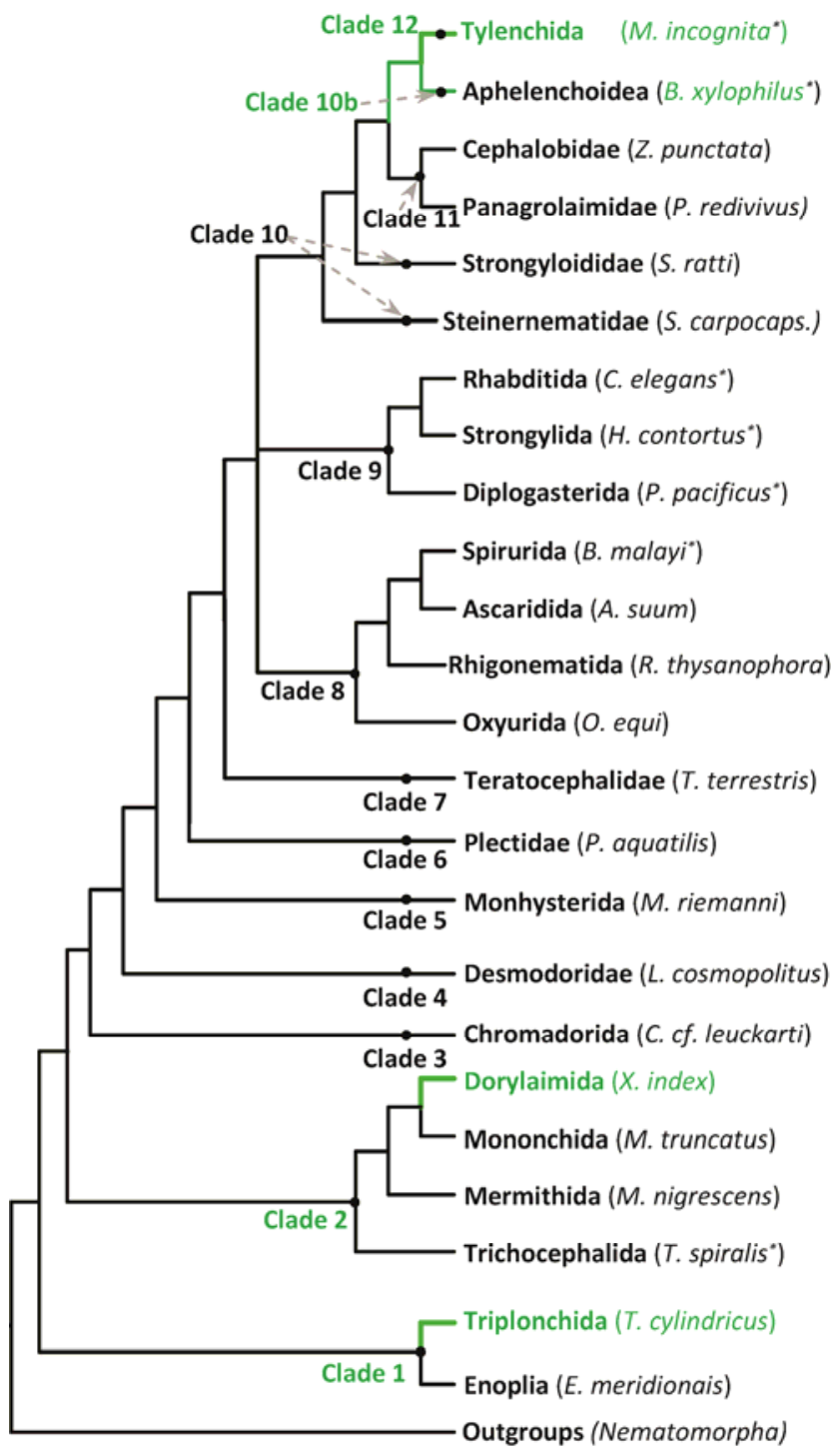

Fig. 1. Schematic representation of the phylogeny of Nematoda. Simplified phylogeny of nematodes with corresponding classification in clades, based on the work of van Megen and associates (2009). Clades that comprise plant-parasitic nematodes are represented in green. For each taxonomic group, the abbreviated name of an example species is given as follows, from top to bottom: Meloidogyne incognita, Bursaphelenchus xylophilus, Zeldia punctata, Panagrellus redivivus, Strongyloides ratti, Steinernema carpocapsae, Caenorhabditis elegans, Haemonchus contortus, Pristionchus pacificus, Brugia malayi, Ascaris suum, Rhigonema thysanophora, Oxyuris equi, Teratocephalus terrestris, Plectus aquatilis, Monhystera riemanni, Laxus cosmopolitus, Chromadorita cf. leuckarti, Xiphinema index, Mononchus truncatus, Mermis nigrescens, Trichinella spiralis, Trichodorus cylindricus, and Enoplus meridionais. An asterisk (*) indicates wholegenome sequence available or under assembly. there is a huge bias towards this clade in terms of the information available as compared to other PPN groups (Figs. 1 and 2, clades $10 \mathrm{~b}, 1$, and 2). Analysis of the information from Tylenchida suggests that extensive HGT has occurred during the evolution of plant parasitism. Numerous plant cell wall-modifying proteins have been identified in these PPN, including cellulases, pectate lyases, xylanases, polygalacturonases, arabinogalactan galactosidases, arabinanases, and expansin-like proteins (Fig. 2). In the genome of Meloidogyne incognita, more than 60 genes belonging to six different protein families involved in plant cell-wall degradation are present (Abad et al. 2008). A comparable diversity is present in M. hapla (Opperman et al. 2008) and in the current assembly of the Globodera pallida genome sequence. Other putative examples of HGT within clade 12 include chorismate mutase (Jones et al. 2003; Lambert et al. 1999), a polyglutamate synthase (Veronico et al. 2001), genes similar to those present in Rhizobium spp. from the pathway encoding nodulation factor synthesis enzymes such as NodL (Scholl et al. 2003), genes involved in the biosynthesis of vitamins B1, B5, B6, and B7 (Craig et al. 2008, 2009), invertase (Abad et al. 2008), and cyanate lyase (Opperman et al. 2008) (Fig. 2).

A series of other PPN genes of as-yet-uncharacterized function may also have originated as a result of HGT, as suggested by their higher similarity to plant, bacterial, or fungal genes than to known nematode genes (Elling et al. 2009; Scholl et al. 2003; Wasmuth et al. 2008). However, these genes have not yet been subjected to detailed phylogenetic analysis and, therefore, need further investigation in order to be confirmed as horizontally acquired.

Although other PPN clades have been less extensively sampled than the Tylenchida, there are several convincing examples of genes that may have been acquired via HGT within these groups. Preliminary evidence exists for the presence of a putative cellulase and an expansin-like protein in the clade 2 migratory ectoparasite Xiphinema index (Jones et al. 2005). The pine wood nematode Bursaphelenchus xylophilus and the related B. mucronatus, both from clade 10b (Fig. 2), have been subjected to extensive EST analysis (Kikuchi et al. 2007). Several cell wall-modifying proteins have been characterized from these species, including cellulases (Kikuchi et al. 2004), pectate lyases (Kikuchi et al. 2006), and expansins (Kikuchi et al. 2009). In addition, B. xylophilus and B. mucronatus have GH16 endo-1,3-beta-glucanases probably involved in degradation of the fungal cell wall and that could have been acquired by HGT from bacteria (Kikuchi et al. 2005).

\section{Distribution of horizontally acquired genes in PPN.}

The observed distribution of genes acquired via HGT ranges from apparently genus-specific events to more widespread transfers shared by PPN from different genera or clades (Fig. 2). Phylogenetic analyses within clade 12 PPN indicate that some genes are conserved in different genera and form monophyletic groups, which suggests a common ancestry and a HGT event that occurred before the diversification of the group (Danchin et al. 2010). For example, the GH5 cellulases are conserved in RKN, Pratylenchidae, CN, and genera Radopholus and Aphelenchus (Fig. 2). This suggests that these cellulases were derived from a same gene acquired via HGT in a common ancestor of clade 12 nematodes. At the other extreme, GH28 polygalacturonases of bacterial origin have only been found to date in RKN and the closely related Pratylenchidae (Haegeman et al. 2011) and may represent a more recent HGT event. Polygalacturonases of family $\mathrm{GH} 28$ have also been reported in Aphelenchus avenae, but phylogenetic analysis indicates a distinct origin and a higher similarity to fungal $\mathrm{GH} 28$ proteins (Karim et al. 2009). To date, only one case of a gene acquired by 
horizontal transfer and shared between two different PPN clades has been reported. An expansin-like protein has been found in $X$. index (clade 2 PPN), and phylogenetic analysis showed that it forms a monophyletic group with the numerous expansins present in clade 12 and clade 10b PPN (Danchin et al. 2010; Haegeman et al. 2010). However, it is unlikely that this monophyly indicates a transfer to the last common ancestor of all these nematodes, as the last common ancestor of clades 2 and 12 is the common ancestor of almost all nematodes. This would imply that a gene was acquired in that ancestor and secondarily lost in all nematode clades except clades 2 and 12. Furthermore, it is commonly considered that plant parasitism does not reflect the lifestyle of the last common nematode ancestor (Blaxter et al. 1998; Holterman et al. 2009). Therefore, it is possible that two independent HGT events from the same or closely related source bacteria underlie the presence of these genes.

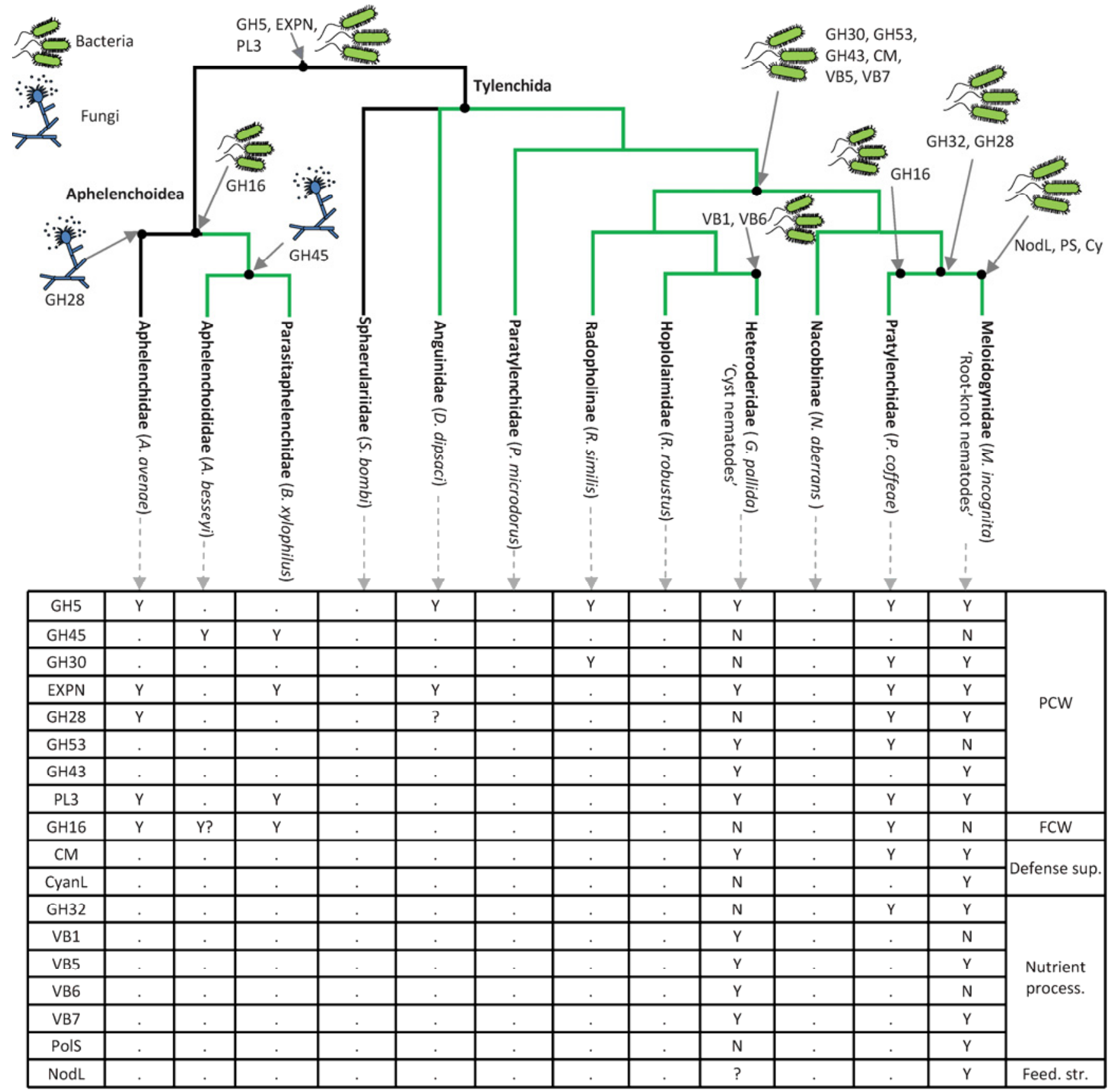

Fig. 2. Distribution of genes acquired via horizontal gene transfer (HGT) in the phylogeny of plant-parasitic nematodes (PPN) from clades 12 and $10 b$. Schematic phylogeny of the major groups of PPN from clades 12 and 10b, based on the works of Holterman and associates (2009) and van Megen and associates (2009). Distribution of genes acquired by HGT is given in the bottom panel. ' $\mathrm{Y}$ ' indicates that the gene has been reported, ' ' indicates that the gene has not yet been reported, and an ' $N$ ' indicates that the gene has been searched in available whole-genome sequences but was not found. Abbreviated gene family names are as follows: GH5 and GH45 = cellulases; GH30 = xylanases; EXPN = expansin-like proteins; GH28 = polygalacturonases; GH53 = candidate arabinogalactan endo-1,4-beta-galactosidases; GH43 = candidate arabinanases; PL3 = pectate lyases; GH16 = beta-1,3-glucanases; CM = chorismate mutases; CyanL = candidate cyanate lyases; GH32 = candidate invertase; VB1, VB5, VB6, and VB7 = genes involved in B1, B5, B6, and B7 vitamin biosynthetic and salvage pathways; PolS = polyglutamate synthase; and NodL = similar to rhizobial nodulation factor NodL. The putative processes in which genes are involved are indicated in the last column. PCW and FCW stands for plant and fungal cell-wall degradation, respectively. Species abbreviated names are as follows from left to right: Aphelenchus avenae, Aphelenchoides besseyi, Bursaphelenchus xylophilus, Sphaerularia bombi, Ditylenchus dipsaci, Paratylenchus microdorus, Radopholus similis, Rotylenchus robustus, Globodera pallida, Nacobbus aberrans, and Pratylenchus coffeae. 
Function of horizontally acquired genes in PPN.

One of the driving forces that promotes successful fixation of genes acquired via HGT is that the gene provides an advantage to the nematode, so that it can be maintained in a population under selective pressure. Four functional roles have been described for the PPN genes thought to have been acquired by HGT: i) modification and degradation of plant or fungal cell walls, ii) suppression of host plant defenses, iii) establishment of the nematode feeding site, and iv) nutrient biosynthesis and processing. Genes falling into the first three of these categories will have a direct role in parasitism, while those in the last category may simply improve the ability to utilize plants as a resource.

The plant cell wall consists mainly of cellulose fibrils crosslinked by hemicelluloses and embedded in a matrix of complex polysaccharides called pectins (Cosgrove 2005). All identified PPN cell wall-modifying enzymes are capable of breaking down one or more of these cell-wall components. Cellulases act on beta-1,4 glycosidic bonds of cellulose (Smant et al. 1998), pectate lyases and polygalacturonases cleave alpha-1,4 linkages of pectate (De Boer et al. 2002; Jaubert et al. 2002; Popeijus et al. 2000), xylanases can degrade xylan (the major component of hemicelluloses) (Mitreva-Dautova et al. 2006), arabinogalactan galactosidases and arabinases are thought to hydrolyze beta-1,4-galactan in the hairy regions of pectin (Vanholme et al. 2009), and expansin-like proteins weaken the noncovalent interactions between cellulose and hemicellulose (Qin et al. 2004), thus exposing these components to the activity of degrading enzymes. All these proteins are expressed in the nematode's subventral gland cells (Fig. 3) and allow the parasite to break the plant cell wall (in combination with the mechanical puncturing of the stylet) during invasion or soften the cell wall in order to allow migration intercellularly (as is the case for Meloidogyne spp.). Moreover, RNA interference assays on transcripts encoding cellulases (Chen et al. 2005) and xylanases (Haegeman et al. 2009a) have both shown reduced infectivity in the PPN, thus reinforcing their active role in parasitism. One of the enzymes acquired by HGT is thought to be important for degradation of fungal cell walls. This enzyme, a GH16 endo-1,3-beta-glucanase, has been identified in various fungivorous and plant-parasitic nematodes from clade 10b, first in Bursaphelenchus species (Kikuchi et al. 2005) and recently in A. avenae (Karim et al. 2009).

Some PPN are biotrophic pathogens that feed on live plant cells for several weeks and therefore need to suppress host defenses for the duration of their life cycles. It has been suggested that some genes acquired by HGT may be important in this process, either as detoxifying agents or as true suppressors of host defense signaling. Candidate cyanate lyases have been identified in the genomes of both M. hapla and M. incognita.

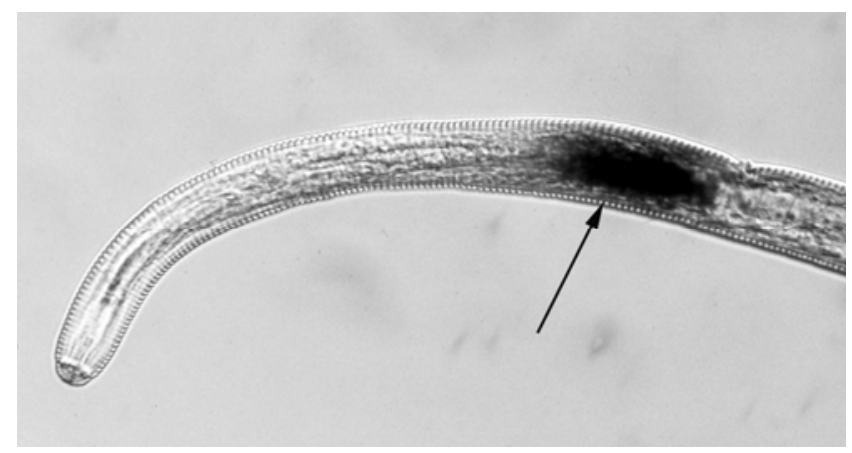

Fig. 3. In situ hybridization image showing expression of a Globodera pallida cellulase. Expression of the cellulase gene (Jones et al. 2009) is restricted to the subventral esophageal gland cell (arrow).
Cyanate can be formed by the plant as a response to attack by herbivores (Jones 1998), and it is known that bacterial cyanate lyases can detoxify cyanate (Johnson and Anderson 1987). Although it is possible that the nematode cyanate lyase has a similar role, it should be noted that the biochemical function remains to be confirmed and also that Meloidogyne spp. are biotrophic not herbivorous. Another horizontally acquired gene that may modulate the plant's defense responses is chorismate mutase. This enzyme is secreted by both RKN and CN (Jones et al. 2003; Lambert et al. 1999) and has recently been described from the migratory endoparasite Pratylenchus coffeae (Haegeman et al. 2011). Chorismate mutase is a key regulatory enzyme in the shikimate pathway in plants and bacteria, and no other enzymes involved in this pathway are present in PPN, strongly suggesting that the nematode enzyme functions in the host plant. Chorismate can be converted via a two-step reaction to the plant defense-signaling compound salicylic acid (SA) (Wildermuth et al. 2001), and it is possible that one role of chorismate mutase may be to reduce the pool of chorismate available for conversion to SA, thus preventing normal activation of host defenses. Alternatively, it has been suggested that chorismate mutase could influence auxin levels in the plant by depleting cytoplasmic pools of chorismate, thus enhancing transport from the plastids in which it would normally be converted to auxins. The resulting auxin depletion could promote the formation of feeding sites (Doyle and Lambert 2003). However, the presence of chorismate mutase in a migratory endoparasitic species that does not induce feeding sites (Haegeman et al. 2011) argues against a role in formation of feeding structures. Prephenate (the product of chorismate mutase activity on chorismate) can be converted to flavonoids. Since flavonoids are natural inhibitors of auxin transport (Jacobs and Rubery 1988), it was suggested that flavonoid accumulation (Hutangura et al. 1999) may be important in manipulation of auxin levels leading to feeding site initiation. However, Arabidopsis mutants deficient in the enzymes downstream of chorismate mutase that synthesize flavonoids are not resistant to nematodes (Jones et al. 2007), arguing against this functional role.

One of the horizontally acquired genes that might be involved in the establishment of the nematode's feeding site is similar to NodL genes from rhizobia (Scholl et al. 2003). Rhizobia are nitrogen-fixing symbiotic soil bacteria that form nodules on the roots of their leguminous hosts. Nodule formation is a complex process requiring lipo-chitooligosaccharide signals from the bacteria (the Nod factors). NodL encodes an $\mathrm{N}$-acetyltransferase involved in the biosynthetic pathway of Nod factors. RKN produce an as-yet-uncharacterized compound that induces changes in roots similar to those induced by Nod factors, and mutant leguminous plants that cannot support normal symbiosis with nodulating bacteria are less susceptible to infection by RKN (Weerasinghe et al. 2005), suggesting some overlap between the signaling pathways underlying symbiosis with nodulating bacteria and nematode feeding-site establishment (Favery et al. 2002).

The last functional category of horizontally transferred genes is nutrient biosynthesis and processing. A total of nine different genes involved in the synthesis or salvage of vitamins B1, B5, B6, and B7 have been identified in CN, and two of these genes are also present in RKN (Craig et al. 2009). B vitamins are essential to all living organisms, but genes involved in their biosynthesis are generally absent from multicellular animals, including the nematode model Caenorhabditis elegans. It is assumed that animals have lost these genes because they are able to extract the required B vitamins from their diet. Although PPN should be able to absorb these vitamins from their feeding sites, plants may restrict the availability of B vitamins 
as a defense mechanism (Craig et al. 2009). Therefore, horizontally acquired genes for biosynthesis and salvage of B vitamins may allow the nematode to circumvent this defense mechanism. Furthermore, genes encoding candidate invertases have been found in RKN (Abad et al. 2008; Bird et al. 2009). Invertases, which are generally absent in animals, convert sucrose - the major form of sugar circulating in plant tissue-into glucose and fructose, which can readily be used as a carbon source by the nematode.

\section{Fate of genes acquired by HGT.}

One feature common to almost all reported cases of genes acquired via HGT in PPN is that they contain multiple spliceosomal introns. Given that the majority of these genes are thought to have had a bacterial origin, and that bacterial homologs lack introns, it is likely that these introns were gained after transfer. An analysis of six different families of plant cell wall-degrading enzymes (CDWE) has shown that all have at least one intron position conserved between different clade 12 and clade 10b nematodes (Danchin et al. 2010). This suggests that these introns were gained before the separation of the different nematode lineages considered and, therefore, soon after their transfer. However, a shared intron position does not necessarily reflect conserved ancestral acquisition of the intron but may occur as a result of "hot spots" of intron gain (Ahmadinejad et al. 2010). Regardless of the mechanism underlying gain of introns, their presence suggests that bacterial genes gained eukaryotic features as part of an adaptation process to their host genome after their acquisition by HGT. Analysis of GC content and codon usage of horizontally acquired genes further support this idea. For example, the GC content of the NodL gene from $M$. incognita is more similar to that of other Meloidogyne genes than to the GC content of genes of rhizobial bacterial species considered as potential donors (Scholl et al. 2003). Similar results were found for 12 other genes described as resulting from HGT in M. incognita (Scholl et al. 2003). The same study also showed that codon usage in the $M$. incognita NodL gene was significantly different from that of a similar rhizobial gene, in spite of the similarity at the amino acid level. Similarly, it was shown that the approximately 60 genes that encode CDWE in $M$. incognita and acquired by horizontal transfer cannot be distinguished from the rest of this nematode's genes on the basis of a comparative analysis of the GC content and codon usage at the whole-genome scale (Danchin et al. 2010). From these examples, it appears that not only did genes acquire introns after their transfer but that their GC content and codon usage have adapted to those of the host genome.

Another feature observed in several instances of HGT is that the acquired genes can form multigene families in PPN. Many of the genes encoding cell wall-modifying proteins, including pectate lyases, cellulase, and expansin-like proteins, are present as large gene families, sometimes displaying considerable sequence divergence. The genome sequence of the RKN $M$. incognita contains approximately 20 cellulases, 30 pectate lyases, and 20 expansin-like proteins. Such multigene families could result from multiple HGT events, from gene duplications, or from a combination of the two phenomena. A phylogenetic analysis of these CDWE showed that their presence as multigene families was due to a series of gene duplications that started soon after one single or a few acquisitions via HGT (Danchin et al. 2010). Gene duplications can promote the emergence of new or more-specialized function through neoor subfunctionalization (Lynch and Conery 2000). Thus, the presence of these genes as multigene families could indicate positive selective pressure that may have favored individuals harboring multiple copies of such genes. Interestingly, it has recently been shown that spontaneous gene duplications occur at a much higher rate than point mutations in C. elegans, suggesting that early adaptive genomic changes could be supported more by advantageous duplications than by beneficial mutations when dosage is under selective pressure (Lipinski et al. 2011).

The most common fate of genes after duplication is their loss, often via pseudogenization (Lynch and Conery 2000). It is, therefore, potentially interesting to study candidate pseudogenes for these families. A recent analysis has allowed identification of candidate pseudogenes encoding altered cellulases in Ditylenchus africanus, but no significant traces of pseudo-endoglucanases were found in the genomes of $M$. incognita and M. hapla (Haegeman et al. 2010). The absence of such stigmata of failed duplications suggests that most genes present in multiple copies in extant RKN genomes have arisen from old duplications.

\section{Nature of potential donors.}

While the output of a simple BLAST (Altschul et al. 1997) search is often used as a crude tool to determine the likely source of a gene acquired via HGT at the kingdom level, identifying a potential source at a finer resolution is extremely challenging, given that the gene is likely to have undergone prolonged evolution within the nematode genome after the HGT event. The presence of introns as well as the similarities in codon usage and GC content to that of the host genome described above suggests that this is, indeed, the case. However, more detailed phylogenetic analysis that includes as many nematode sequences as possible as well as sequences from a broad range of species in the taxonomic clade from which the HGT event is suspected to have occurred can often provide an indication as to the likely source of the gene and allows speculation as to the mode of transfer.

A detailed analysis of the HGT candidates that gave rise to the repertoire of plant CDWE in Tylenchida (Danchin et al. 2010) has allowed the likely patterns of HGT and candidate donors for many of these to be identified. In some cases this analysis revealed a clear candidate for the origin of the gene. For example, the nematode GH28 polygalacturonases form a well-supported cluster when analyzed with bacterial sequences, and a cluster of GH28 enzymes from the bacterium Ralstonia solanacearum resides within the cluster of nematode genes (Danchin et al. 2010). In many cases, nematode genes seem to be most closely related to sequences from soil bacteria, and it is intriguing to note that, in several cases, the nematode CDWE may have been acquired from plant-pathogenic or plant-associated bacteria. Although the absence of a wide range of nematode sequences means that no detailed phylogeny has been performed, the same is likely to be true for the NodL sequence identified from M. incognita (Scholl et al. 2003) and M. hapla (Opperman et al. 2008), which shows highest similarity to sequences from Rhizobium spp.. The GH16 endo1,3-beta-glucanases from B. xylophilus and A. avenae (Karim et al. 2009; Kikuchi et al. 2005) are also most similar to bacterial sequences. It is interesting to note that one of the closest relatives is a GH16 sequence from Chitinophaga pinensis, a bacterium capable of degrading chitin that was originally isolated from litter at the base of a pine tree. In addition to the GH16 endoglucanases, Bursaphelenchus species also have GH45 cellulases. Unlike the other horizontally acquired genes discussed above, it is very likely that these have been acquired from fungi rather than bacteria (Kikuchi et al. 2004). Similarly, the GH28 enzyme found in A. avenae also appears to be of fungal origin (Karim et al. 2009).

Large-scale bioinformatic screens of nematode EST have provided some evidence that PPN may have also acquired genes from their host plants (Elling et al. 2009; Wasmuth et al. 
2008). Nematode transcripts showing highest sequence similarity to plant genes have been identified in these studies, but no phylogenetic analysis has been conducted, and no indication of the putative function of the genes is currently available. Cyst nematodes have genes that encode proteins, including peptides functionally analogous to CLAVATA3/ESR peptides from plants (Lu et al. 2009; Olsen and Skriver 2003). The peptides can complement cle3-1 mutants of Arabidopsis thaliana, and overexpression of the peptides induces a phenotype consistent with downregulation of WUSCHEL in plants (Wang et al. 2005). In spite of the functional and sequence similarity of the nematode and plant peptides, it is thought that the nematode proteins have evolved as mimics of the host peptides rather than being acquired by HGT. It is, therefore, important to be aware of the potential for evolution of mimetics when considering potential HGT candidates.

\section{Potential mechanisms of transfer.}

Attempting to determine the mechanisms underlying HGT events on the basis of isolated sequence data alone is inevitably a speculative undertaking. However, complete genome sequence data are available for two Meloidogyne species and will shortly be available for at least one cyst nematode ( $G$. pallida) and for B. xylophilus (T. Kikuchi, personal communication), allowing analysis of the sequences in the vicinity of horizontally acquired genes.

HGT from intracellular symbiotic bacteria, such as Wolbachia spp., to their eukaryotic hosts, including animal-parasitic nematodes such as Brugia malayi, has been described (Dunning Hotopp et al. 2007). Some of the PPN discussed here are known to harbor endosymbionts (Haegeman et al. 2009b; Noel and Atibalentja 2006), and these are often found in reproductive tissues, including developing gametes, offering a plausible route for HGT of heritable DNA fragments to nematodes. However, the symbiotic bacteria currently described from nematodes are not known to encode any of the CWDE that have been acquired and none of the horizontally acquired genes give strong matches to any Wolbachia sequences. Given the timescales that are likely to have elapsed since the HGT events have occurred, it is feasible that the ancestors of plant-parasitic nematodes had a symbiotic relationship with a bacterium from which the genes were acquired and that this bacterium has subsequently been lost, as the selective pressure for retaining the symbiont would be lost once the nematode was capable of producing its own CDWE.

A common feature in many cases of HGT, regardless of their putative fungal or bacterial origin, is that the suspected donor species share the same or a similar ecological niche as the receiver nematodes. Thus, it is tempting to hypothesize that ancestors of PPN acquired the genes by feeding on bacteria or fungi involved in parasitic or symbiotic interactions with plants. This has been presented as the 'you are what you eat' hypothesis (Doolittle 1998). However, it appears conceptually difficult to explain how a gene present in the diet can pass through the digestive-tube barrier and then be successfully inserted in an intact form in the nuclear genome of the germline in order to be transmitted to the offspring. When RNAi is induced systemically by feeding, double-stranded RNA is taken up via the gut and spreads throughout the nematode body. However, it is not known whether DNA can be transported by this system. Acquisition of genes from the diet has been described in a sea slug that feeds on algae, although this remains to be confirmed using larger scale analysis (Rumpho et al. 2011). Given this, it is interesting to note that among the nematodes most closely related to PPN of clades 12 and 10 are several species that feed on bacteria and are known to spend at least part of their life cycle inside plant tissues (Westcott and Barker
1976). It can, therefore, be hypothesized that PPN evolved from fungivorous or bacteriovorous nematodes that acquired genes involved in plant parasitism from their diet.

This does not provide a mechanistic explanation as to how the sequences were transferred to nematodes in a heritable form. Transposable elements offer a plausible explanation as to how fragments of DNA may have been moved from bacteria to nematodes, and there are well-documented examples of lateral transmission of some classes of transposons (Robertson 1993). Bdelloid rotifers have acquired numerous genes by HGT, and these genes have been shown to be associated with transposable elements (Gladyshev et al. 2008). However, no such clear association between HGT genes and transposable elements is immediately evident from the Meloidogyne genome sequences.

It can also be hypothesized that viruses or plasmids (e.g., similar to Agrobacterium Ti plasmids) may have been vectors for transmission of genes from microorganisms to the nuclear genomes of nematodes. With this in mind, it is interesting to note that genome sequencing has revealed the presence of type IV secretion systems that may allow transfer of DNA to other organisms in a broader range of bacterial species than originally anticipated (Bell et al. 2004). Furthermore, analysis of three genome sequences of parasitoid wasps suggested tri-lateral HGT between Wolbachia endosymbionts, Pox viruses, and the parasitoid arthropods (Werren et al. 2010).

\section{HGT in other nematodes.}

Although there are more examples of putative HGT in plantparasitic nematodes than in any other trophic group, HGT events have also been reported in other nematode species. One of the most interesting findings is the presence of putative cellulases in the necromeric nematode Pristionchus pacificus and in related species in clade 9 (Dieterich et al. 2008; Mayer et al. 2011). The function of these cellulases is unclear, but it has been hypothesized that they could degrade cellulose present in the biofilm of bacteria on which these nematodes feed (Mayer et al. 2011). Although the Pristionchus cellulases, like those from the Tylenchida, are from family GH5, they have a different origin and have a different carbohydrate binding module (CBM49 instead of CBM2) appended. These GH5 cellulases are more closely related to those from the genus Amoeba, while GH5 cellulases found in PPN are related to bacterial genes (Mayer et al. 2011).

Although the genome of the free-living nematode C. elegans has been available since 1998 (The C. elegans Genome Sequencing Consortium 1998), few studies have examined this genome in detail for potential HGT candidates. However, there is some evidence that two enzymes from the glyoxylate cycle, isocitrate lyase and malate synthase, may have been acquired into the Caenorhabditis lineage following HGT from bacteria (Kondrashov et al. 2006). In animal-parasitic nematodes, multiple HGT events have been reported, primarily linked to bacterial endosymbionts. The genome sequence of the filarial nematode Brugia malayi contains several traces of its Wolbachia endosymbiont. Comparison with the original Wolbachia sequences suggests that these horizontally transferred genes are degenerate (Dunning Hotopp et al. 2007). In other filarial nematodes that do not harbor a Wolbachia symbiont, such as Acanthocheilonema viteae and Onchocerca flexuosa, similar traces of horizontally transferred Wolbachia genes are present. It has been hypothesized that Wolbachia DNA became part of the nuclear genome of an ancestor of these species via HGT prior to loss of the endosymbiont (McNulty et al. 2010).

\section{Concluding remarks.}

Genes of bacterial or fungal origin, encoding plant CDWE have been found in all PPN species that have been examined at 
the molecular level in any detail. It is tempting to speculate that these genes (and therefore HGT) have played a crucial role in the evolution of plant-parasitism in nematodes on each occasion that it has arisen. Plant parasitism is thought to have evolved independently at least three times in the evolutionary history of nematodes, since phytoparasites are found in distinct and evolutionary distant clades (Fig. 1). Genes acquired by HGT and with functions clearly linked to plant parasitism have been reported in Tylenchida (clade 12), Aphelenchoidea (clade 10b), and Dorylaimida (clade 2). However, plant-parasitic nematodes have also been described in clade 1 (e.g., Trichodoridae), but due to the lack of sequence information, it is not known whether horizontal transfer of genes with a role in parasitism has also occurred. Identification of genes of foreign origin in this clade would reinforce the importance of HGT in the evolution of plant parasitism in nematodes.

More generally, extensive analysis of the distribution of horizontally acquired genes is difficult due to the limited number of plant-parasitic nematode genomes currently available. In addition, representatives of potentially interesting nematode clades may be rare or difficult, or both, to culture. However, the decreasing costs of large-scale sequence analysis coupled to the development of bioinformatics tools accessible to labbased researchers mean that increasingly large numbers of nematode species are being analyzed, improving the underlying dataset available for tracking HGT events.

While it is recognized that HGT events have played important adaptive roles in the evolutionary history of prokaryotes, the idea that they may have also played significant roles in animals is only now being accepted (Dunning Hotopp 2011). This is possibly due to the fact that most HGT events reported in animals did not present convincing evidence for a functional role in the host species. Recently, genes transferred from fungi to pea aphids have been shown to be involved in the pigmentation of these species, an important feature in the ecology of these insects feeding on plants (Moran and Jarvik 2010). In plant-parasitic nematodes, much evidence has been accumulated showing that genes acquired from bacteria and fungi are successfully transcribed and translated. The biochemical function of those that have been experimentally characterized can clearly be linked to adaptations to plant parasitism. Thus it is evident that HGT has played an important role in PPN. Whether HGT has also had a significant role in the adaptation of other animal lineages will probably be deciphered soon, as such events become systematically tracked in the ever-growing set of available whole genomes.

\section{ACKNOWLEDGMENTS}

The Scottish Crop Research Institute (SCRI, Invergowrie, U.K.) receives funding from the Scottish government. This work benefited from links funded through COST Action 872. A. Haegeman is funded by a postdoctoral grant from the Flanders Research Foundation (FWO). The authors are grateful to M. N. Rosso (Institut National de la Recherche Agronomique Sophia-Antipolis, France), S. Mantelin (SCRI), and G. Gheysen (Ghent University, Belgium) for advice, discussions, and critical review of the manuscript.

\section{LITERATURE CITED}

Abad, P., Gouzy, J., Aury, J. M., Castagnone-Sereno, P., Danchin, E. G., Deleury, E., Perfus-Barbeoch, L., Anthouard, V., Artiguenave, F., Blok, V. C., Caillaud, M. C., Coutinho, P. M., Dasilva, C., De Luca, F., Deau, F., Esquibet, M., Flutre, T., Goldstone, J. V., Hamamouch, N., Hewezi, T., Jaillon, O., Jubin, C., Leonetti, P., Magliano, M., Maier, T. R., Markov, G. V., McVeigh, P., Pesole, G., Poulain, J., Robinson-Rechavi, M., Sallet, E., Segurens, B., Steinbach, D., Tytgat, T., Ugarte, E., van Ghelder, C., Veronico, P., Baum, T. J., Blaxter, M., Bleve-Zacheo, T., Davis, E. L., Ewbank, J. J., Favery, B., Grenier, E., Henrissat, B., Jones,
J. T., Laudet, V., Maule, A. G., Quesneville, H., Rosso, M. N., Schiex, T., Smant, G., Weissenbach, J., and Wincker, P. 2008. Genome sequence of the metazoan plant-parasitic nematode Meloidogyne incognita. Nat. Biotechnol. 26:909-915.

Ahmadinejad, N., Dagan, T., Gruenheit, N., Martin, W., and Gabaldon, T. 2010. Evolution of spliceosomal introns following endosymbiotic gene transfer. BMC Evol. Biol. 10:57.

Altschul, S. F., Madden, T. L., Schaffer, A. A., Zhang, J., Zhang, Z. Miller, W., and Lipman, D. J. 1997. Gapped BLAST and PSI-BLAST: A new generation of protein database search programs. Nucleic Acids Res. 25:3389-3402

Andersson, J. O. 2005. Lateral gene transfer in eukaryotes. Cell Mol. Life Sci. 62:1182-1197.

Bell, K. S., Sebaihia, M., Pritchard, L., Holden, M. T., Hyman, L. J., Holeva, M. C., Thomson, N. R., Bentley, S. D., Churcher, L. J., Mungall, K., Atkin, R., Bason, N., Brooks, K., Chillingworth, T., Clark, K., Doggett, J., Fraser, A., Hance, Z., Hauser, H., Jagels, K., Moule, S., Norbertczak, H., Ormond, D., Price, C., Quail, M. A., Sanders, M., Walker, D., Whitehead, S., Salmond, G. P., Birch, P. R., Parkhill, J., and Toth, I. K. 2004. Genome sequence of the enterobacterial phytopathogen Erwinia carotovora subsp. atroseptica and characterization of virulence factors. Proc. Natl. Acad. Sci. U.S.A. 101:11105-11110.

Bird, D. M., Williamson, V. M., Abad, P., McCarter, J., Danchin, E. G., Castagnone-Sereno, P., and Opperman, C. H. 2009. The genomes of root-knot nematodes. Annu. Rev. Phytopathol. 47:333-351.

Blaxter, M. L., De Ley, P., Garey, J. R., Liu, L. X., Scheldeman, P., Vierstraete, A., Vanfleteren, J. R., Mackey, L. Y., Dorris, M., Frisse, L. M., Vida, J. T., and Thomas, W. K. 1998. A molecular evolutionary framework for the phylum Nematoda. Nature 392:71-75.

The C. elegans Genome Sequencing Consortium. 1998. Genome sequence of the nematode C. elegans: A platform for investigating biology. Science 282:2012-2018

Chen, Q., Rehman, S., Smant, G., and Jones, J. T. 2005. Functional analysis of pathogenicity proteins of the potato cyst nematode Globodera rostochiensis using RNAi. Mol. Plant-Microbe Interact. 18:621-625.

Cosgrove, D. J. 2005. Growth of the plant cell wall. Nat. Rev. Mol. Cell Biol. 6:850-861.

Craig, J. P., Bekal, S., Hudson, M., Domier, L., Niblack, T., and Lambert, K. N. 2008. Analysis of a horizontally transferred pathway involved in vitamin B6 biosynthesis from the soybean cyst nematode Heterodera glycines. Mol. Biol. Evol. 25:2085-2098.

Craig, J. P., Bekal, S., Niblack, T., Domier, L., and Lambert, K. N. 2009. Evidence for horizontally transferred genes involved in the biosynthesis of vitamin B-1, B-5, and B-7 in Heterodera glycines. J. Nematol. 41:281-290.

Danchin, E. G., Rosso, M. N., Vieira, P., de Almeida-Engler, J., Coutinho, P. M., Henrissat, B., and Abad, P. 2010. Multiple lateral gene transfers and duplications have promoted plant parasitism ability in nematodes. Proc. Natl. Acad. Sci. U.S.A. 107:17651-17656.

De Boer, J. M., Davis, E. L., Hussey, R. S., Popeijus, H., Smant, G., and Baum, T. J. 2002. Cloning of a putative pectate lyase gene expressed in the subventral esophageal glands of Heterodera glycines. J. Nematol. 34:9-11.

Dieterich, C., Clifton, S. W., Schuster, L. N., Chinwalla, A., Delehaunty, K., Dinkelacker, I., Fulton, L., Fulton, R., Godfrey, J., Minx, P., Mitreva, M., Roeseler, W., Tian, H., Witte, H., Yang, S. P., Wilson, R. K., and Sommer, R. J. 2008. The Pristionchus pacificus genome provides a unique perspective on nematode lifestyle and parasitism. Nat. Genet. 40:1193-1198.

Doolittle, W. F. 1998. You are what you eat: A gene transfer ratchet could account for bacterial genes in eukaryotic nuclear genomes. Trends Genet. 14:307-311.

Doyle, E. A., and Lambert, K. N. 2003. Meloidogyne javanica chorismate mutase 1 alters plant cell development. Mol. Plant-Microbe Interact. 16:123-131.

Dropkin, V. 1963. Cellulase in phytoparasitic nematodes. Nematologica 9:444-454.

Dunning Hotopp, J. C. 2011. Horizontal gene transfer between bacteria and animals. Trends Genet. 27:157-163.

Dunning Hotopp, J. C., Clark, M. E., Oliveira, D. C., Foster, J. M., Fischer, P., Torres, M. C., Giebel, J. D., Kumar, N., Ishmael, N., Wang, S., Ingram, J., Nene, R. V., Shepard, J., Tomkins, J., Richards, S., Spiro, D. J., Ghedin, E., Slatko, B. E., Tettelin, H., and Werren, J. H. 2007. Widespread lateral gene transfer from intracellular bacteria to multicellular eukaryotes. Science 317:1753-1756.

Elling, A. A., Mitreva, M., Gai, X., Martin, J., Recknor, J., Davis, E. L., Hussey, R. S., Nettleton, D., McCarter, J. P., and Baum, T. J. 2009. Sequence mining and transcript profiling to explore cyst nematode parasitism. BMC Genomics 10:58.

Favery, B., Complainville, A., Vinardell, J. M., Lecomte, P., Vaubert, D., 
Mergaert, P., Kondorosi, A., Kondorosi, E., Crespi, M., and Abad, P. 2002. The endosymbiosis-induced genes ENOD4O and CCS52a are involved in endoparasitic-nematode interactions in Medicago truncatula. Mol. Plant-Microbe Interact. 15:1008-1013.

Gladyshev, E. A., Meselson, M., and Arkhipova, I. R. 2008. Massive horizontal gene transfer in bdelloid rotifers. Science 320:1210-1213.

Haegeman, A., Vanholme, B., and Gheysen, G. 2009a. Characterization of a putative endoxylanase in the migratory plant-parasitic nematode $\mathrm{Ra}-$ dopholus similis. Mol. Plant Pathol. 10:389-401.

Haegeman, A., Vanholme, B., Jacob, J., Vandekerckhove, T. T., Claeys, M., Borgonie, G., and Gheysen, G. 2009b. An endosymbiotic bacterium in a plant-parasitic nematode: Member of a new Wolbachia supergroup. Int. J. Parasitol. 39:1045-1054.

Haegeman, A., Kyndt, T., and Gheysen, G. 2010. The role of pseudo-endoglucanases in the evolution of nematode cell wall-modifying proteins. J. Mol. Evol. 70:441-452.

Haegeman, A., Joseph, S., and Gheysen, G. 2011. Analysis of the transcriptome of the root lesion nematode Pratylenchus coffeae generated by 454 sequencing technology. Mol. Biochem. Parasitol. (In press). Mol. Biochem. Parasitol. 178:7-14

Holterman, M., Karssen, G., van den Elsen, S., van Megen, H., Bakker, J., and Helder, J. 2009. Small subunit rDNA-based phylogeny of the Tylenchida sheds light on relationships among some high-impact plantparasitic nematodes and the evolution of plant feeding. Phytopathology 99:227-235.

Hutangura, P., Mathesius, U., Jones, M. G. K., and Rolfe, B. G. 1999. Auxin induction is a trigger for root gall formation caused by root-knot nematodes in white clover and is associated with the activation of the flavonoid pathway. Austr. J. Plant Physiol. 26:221-231.

Jacobs, M., and Rubery, P. H. 1988. Naturally occurring auxin transport regulators. Science 241:346-349.

Jaubert, S., Laffaire, J. B., Abad, P., and Rosso, M. N. 2002. A polygalacturonase of animal origin isolated from the root-knot nematode Meloidogyne incognita. FEBS (Fed. Eur. Biochem. Soc.) Lett. 522:109-112.

Johnson, W. V., and Anderson, P. M. 1987. Bicarbonate is a recycling substrate for cyanase. J. Biol. Chem. 262:9021-9025.

Jones, D. A. 1998. Why are so many food plants cyanogenic? Phytochemistry $47: 155-162$

Jones, J. T., Furlanetto, C., Bakker, E., Banks, B., Blok, V., Chen, Q. Phillips, M., and Prior, A. 2003. Characterization of a chorismate mutase from the potato cyst nematode Globodera pallida. Mol. Plant Pathol. 4:43-50.

Jones, J. T., Furlanetto, C., and Kikuchi, T. 2005. Horizontal gene transfer from bacteria and fungi as a driving force in the evolution of plant parasitism in nematodes. Nematology 7:641-646.

Jones, J. T., Furlanetto, C., and Phillips, M. S. 2007. The role of flavonoids produced in response to cyst nematode infection of Arabidopsis thaliana. Nematology 9:671-677.

Jones, J. T., Kumar, A., Pylypenko, L. A., Thirugnanasambandam, A., Castelli, L., Chapman, S., Cock, P. J., Grenier, E., Lilley, C. J., Phillips, M. S., and Blok, V. C. 2009. Identification and functional characterization of effectors in expressed sequence tags from various life cycle stages of the potato cyst nematode Globodera pallida. Mol. Plant Pathol. 10:815-828

Karim, N., Jones, J. T., Okada, H., and Kikuchi, T. 2009. Analysis of expressed sequence tags and identification of genes encoding cell-walldegrading enzymes from the fungivorous nematode Aphelenchus avenae. BMC Genomics 10:525.

Keeling, P. J., and Palmer, J. D. 2008. Horizontal gene transfer in eukaryotic evolution. Nat. Rev. Genet. 9:605-618.

Keen, N. T., and Roberts, P. A. 1998. Plant parasitic nematodes: Digesting a page from the microbe book. Proc. Natl. Acad. Sci. U.S.A. 95:47894790.

Kikuchi, T., Jones, J. T., Aikawa, T., Kosaka, H., and Ogura, N. 2004. A family of glycosyl hydrolase family 45 cellulases from the pine wood nematode Bursaphelenchus xylophilus. FEBS (Fed. Eur. Biochem. Soc.) Lett. 572:201-205.

Kikuchi, T., Shibuya, H., and Jones, J. T. 2005. Molecular and biochemical characterization of an endo-beta-1,3-glucanase from the pinewood nematode Bursaphelenchus xylophilus acquired by horizontal gene transfer from bacteria. Biochem. J. 389:117-125.

Kikuchi, T., Shibuya, H., Aikawa, T., and Jones, J. T. 2006. Cloning and characterization of pectate lyases expressed in the esophageal gland of the pine wood nematode Bursaphelenchus xylophilus. Mol. PlantMicrobe Interact. 19:280-287.

Kikuchi, T., Aikawa, T., Kosaka, H., Pritchard, L., Ogura, N., and Jones, J. T. 2007. Expressed sequence tag (EST) analysis of the pine wood nematode Bursaphelenchus xylophilus and B. mucronatus. Mol. Biochem. Parasitol. 155:9-17.

Kikuchi, T., Li, H., Karim, N., Kennedy, M. W., Moens, M., and Jones, J.
T. 2009. Identification of putative expansin-like genes from the pine wood nematode, Bursaphelenchus xylophilus, and evolution of the expansin gene family within the Nematoda. Nematology 11:355-364.

Kondrashov, F. A., Koonin, E. V., Morgunov, I. G., Finogenova, T. V., and Kondrashova, M. N. 2006. Evolution of glyoxylate cycle enzymes in Metazoa: Evidence of multiple horizontal transfer events and pseudogene formation. Biol. Direct 1:31.

Lambert, K. N., Allen, K. D., and Sussex, I. M. 1999. Cloning and characterization of an esophageal-gland-specific chorismate mutase from the phytoparasitic nematode Meloidogyne javanica. Mol. Plant-Microbe Interact. 12:328-336.

Lipinski, K. J., Farslow, J. C., Fitzpatrick, K. A., Lynch, M., Katju, V., and Bergthorsson, U. 2011. High spontaneous rate of gene duplication in Caenorhabditis elegans. Curr. Biol. 21:306-310.

Lu, S.-W., Chen, S., Wang, J., Yu, H., Chronis, D., Mitchum, M. G., and Wang, X. 2009. Structural and functional diversity of CLAVATA3/ESR $(C L E)$-like genes from the potato cyst nematode Globodera rostochiensis. Mol. Plant-Microbe Interact. 22:1128-1142.

Lynch, M., and Conery, J.S. 2000. The evolutionary fate and consequences of duplicate genes. Science 290:1151-1155.

Mayer, W. E., Schuster, L. N., Bartelmes, G., Dieterich, C., and Sommer, R. J. 2011. Horizontal gene transfer of microbial cellulases into nematode genomes is associated with functional assimilation and gene turnover. BMC Evol. Biol. 11:13

McNulty, S. N., Foster, J. M., Mitreva, M., Dunning Hotopp, J. C., Martin, J., Fischer, K., Wu, B., Davis, P. J., Kumar, S., Brattig, N. W., Slatko, B. E., Weil, G. J., and Fischer, P. U. 2010. Endosymbiont DNA in endobacteria-free filarial nematodes indicates ancient horizontal genetic transfer. PLoS One 5:e11029. Published online

Mitreva, M., Smant, G., and Helder, J. 2009. Role of horizontal gene transfer in the evolution of plant parasitism among nematodes. Method Mol. Biol. 532:517-535.

Mitreva-Dautova, M., Roze, E., Overmars, H., de Graaff, L., Schots, A., Helder, J., Goverse, A., Bakker, J., and Smant, G. 2006. A symbiont-independent endo-1,4- $\beta$-xylanase from the plant-parasitic nematode Meloidogyne incognita. Mol. Plant-Microbe Interact. 19:521-529.

Moran, N. A., and Jarvik, T. 2010. Lateral transfer of genes from fungi underlies carotenoid production in aphids. Science 328:624-627.

Nakamura, Y., Itoh, T., Matsuda, H., and Gojobori, T. 2004. Biased biological functions of horizontally transferred genes in prokaryotic genomes. Nat Genet 36:760-766.

Noel, G. R., and Atibalentja, N. 2006. 'Candidatus Paenicardinium endonii', an endosymbiont of the plant-parasitic nematode Heterodera glycines (Nemata: Tylenchida), affiliated to the phylum Bacteroidetes. Internatl J. System. Evol. Microbiol. 56:1697-1702.

Olsen, A. N., and Skriver, K. 2003. Ligand mimicry? Plant-parasitic nematode polypeptide with similarity to CLAVATA3. Trends Plant Sci. 8:5557.

Opperman, C. H., Bird, D. M., Williamson, V. M., Rokhsar, D. S., Burke, M., Cohn, J., Cromer, J., Diener, S., Gajan, J., Graham, S., Houfek, T. D., Liu, Q., Mitros, T., Schaff, J., Schaffer, R., Scholl, E., Sosinski, B. R., Thomas, V. P., and Windham, E. 2008. Sequence and genetic map of Meloidogyne hapla: A compact nematode genome for plant parasitism. Proc. Natl. Acad. Sci. U.S.A. 105:14802-14807.

Popeijus, H., Overmars, H., Jones, J., Blok, V., Goverse, A., Helder, J., Schots, A., Bakker, J., and Smant, G. 2000. Degradation of plant cell walls by a nematode. Nature 406:36-37.

Qin, L., Kudla, U., Roze, E. H., Goverse, A., Popeijus, H., Nieuwland, J., Overmars, H., Jones, J. T., Schots, A., Smant, G., Bakker, J., and Helder, J. 2004. Plant degradation: A nematode expansin acting on plants. Nature 427:30.

Robertson, H. M. 1993. The mariner transposable element is widespread in insects. Nature 362:241-245.

Rumpho, M. E., Pelletreau, K. N., Moustafa, A., and Bhattacharya, D. 2011. The making of a photosynthetic animal. J. Exp. Biol. 214:303311.

Scholl, E. H., Thorne, J. L., McCarter, J. P., and Bird, D. M. 2003. Horizontally transferred genes in plant-parasitic nematodes: A high-throughput genomic approach. Genome Biol. 4:R39.

Smant, G., Stokkermans, J. P., Yan, Y., de Boer, J. M., Baum, T. J., Wang, X., Hussey, R. S., Gommers, F. J., Henrissat, B., Davis, E. L., Helder, J., Schots, A., and Bakker, J. 1998. Endogenous cellulases in animals: Isolation of beta-1, 4-endoglucanase genes from two species of plantparasitic cyst nematodes. Proc. Natl. Acad. Sci. U.S.A. 95:4906-4911.

van Megen, H., van den Elsen, S., Holterman, M., Karssen, G., Mooyman, P., Bongers, T., Holovachov, O., Bakker, J., and Helder, J. 2009. A phylogenetic tree of nematodes based on about 1200 full-length small subunit ribosomal DNA sequences. Nematology 11:927-950.

Vanholme, B., Haegeman, A., Jacob, J., Cannoot, B., and Gheysen, G. 2009. Arabinogalactan endo-1,4-beta-galactosidase: A putative plant 
cell wall-degrading enzyme of plant-parasitic nematodes. Nematology 11:739-747.

Veronico, P., Jones, J., Di Vito, M., and De Giorgi, C. 2001. Horizontal transfer of a bacterial gene involved in polyglutamate biosynthesis to the plant-parasitic nematode Meloidogyne artiellia. FEBS (Fed. Eur. Biochem. Soc.) Lett. 508:470-474.

Walton, J. D. 1994. Deconstructing the cell wall. Plant Physiol 104:11131118 .

Wang, X., Mitchum, M. G., Gao, B., Li, C., Diab, H., Baum, T. J., Hussey, R. S., and Davis, E. L. 2005. A parasitism gene from a plant-parasitic nematode with function similar to CLAVATA3/ESR (CLE) of Arabidopsis thaliana. Mol. Plant Pathol. 6:187-191.

Wasmuth, J., Schmid, R., Hedley, A., and Blaxter, M. 2008. On the extent and origins of genic novelty in the phylum nematoda. PLoS Neglect. Trop. Dis. 2:e258. Published online.

Weerasinghe, R. R., Bird, D. M., and Allen, N. S. 2005. Root-knot nematodes and bacterial Nod factors elicit common signal transduction events in Lotus japonicus. Proc. Natl. Acad. Sci. U.S.A. 102:31473152.

Werren, J. H., Richards, S., Desjardins, C. A., Niehuis, O., Gadau, J., Colbourne, J. K., Werren, J. H., Richards, S., Desjardins, C. A., Niehuis, O., Gadau, J., Colbourne, J. K., Beukeboom, L. W., Desplan, C., Elsik, C. G., Grimmelikhuijzen, C. J., Kitts, P., Lynch, J. A., Murphy, T., Oliveira, D. C., Smith, C. D., van de Zande, L., Worley, K. C., Zdobnov, E. M., Aerts, M., Albert, S., Anaya, V. H., Anzola, J. M., Barchuk, A. R., Behura, S. K., Bera, A. N., Berenbaum, M. R., Bertossa, R. C., Bitondi, M. M., Bordenstein, S. R., Bork, P., Bornberg-Bauer, E., Brunain, M., Cazzamali, G., Chaboub, L., Chacko, J., Chavez, D., Childers, C. P., Choi, J. H., Clark, M. E., Claudianos, C., Clinton, R. A., Cree, A. G., Cristino, A. S., Dang, P. M., Darby, A. C., de Graaf, D. C.,
Devreese, B., Dinh, H. H., Edwards, R., Elango, N., Elhaik, E., Ermolaeva, O., Evans, J. D., Foret, S., Fowler, G. R., Gerlach, D., Gibson, J. D., Gilbert, D. G., Graur, D., Grunder, S., Hagen, D. E., Han, Y., Hauser, F., Hultmark, D., Hunter, H. C., Hurst, G. D., Jhangian, S. N., Jiang, H., Johnson, R. M., Jones, A. K., Junier, T., Kadowaki, T., Kamping, A., Kapustin, Y., Kechavarzi, B., Kim, J., Kim, J., Kiryutin, B., Koevoets, T., Kovar, C. L., Kriventseva, E. V., Kucharski, R., Lee, H., Lee, S. L., Lees, K., Lewis, L. R., Loehlin, D. W., Logsdon, J. M., Jr., Lopez, J. A., Lozado, R. J., Maglott, D., Maleszka, R., Mayampurath, A., Mazur, D. J., McClure, M. A., Moore, A. D., Morgan, M. B., Muller, J., Munoz-Torres, M. C., Muzny, D. M., Nazareth, L. V., Neupert, S., Nguyen, N. B., Nunes, F. M., Oakeshott, J. G., Okwuonu, G. O., Pannebakker, B. A., Pejaver, V. R., Peng, Z., Pratt, S. C., Predel, R., Pu, L. L., Ranson, H., Raychoudhury, R., Rechtsteiner, A., Reese, J. T., Reid, J. G., Riddle, M. Robertson, H. M., Romero-Severson, J., Rosenberg, M., Sackton, T. B. Sattelle, D. B., Schluns, H., Schmitt, T., Schneider, M., Schuler, A. Schurko, A. M., Shuker, D. M., Simoes, Z. L., Sinha, S., Smith, Z. Solovyev, V., Souvorov, A., Springauf, A., Stafflinger, E., Stage, D. E., Stanke, M., Tanaka, Y., Telschow, A., Trent, C., Vattathil, S., Verhulst, E. C., Viljakainen, L., Wanner, K. W., Waterhouse, R. M., Whitfield, J. B., Wilkes, T. E., Williamson, M., Willis, J. H., Wolschin, F., Wyder, S., Yamada, T., Yi, S. V., Zecher, C. N., Zhang, L., and Gibbs, R. A. 2010 Functional and evolutionary insights from the genomes of three parasitoid Nasonia species. Science 327:343-348.

Westcott, S. W., and Barker, K. R. 1976. Interaction of Acrobeloides buetschlii and Rhizobium leguminosarum on wando pea. Phytopathology 66:468-472.

Wildermuth, M. C., Dewdney, J., Wu, G., and Ausubel, F. M. 2001. Isochorismate synthase is required to synthesize salicylic acid for plant defence. Nature 414:562-565. 